\title{
Relationship Between Chronic Pain and Quality of Life in Patients With Acute Leukemia Undergoing Chemotherapy
}

\author{
Mojtaba Miladinia ${ }^{1}$; Shahram Baraz ${ }^{1,{ }^{*}}$; Abdolali Shariati ${ }^{1}$; Amal Saki Malehi ${ }^{2}$; Ahmad \\ Amadzadeh $^{3}$ \\ ${ }_{2}^{1}$ Chronic Diseases Care Research Center, School of Nursing and Midwifery, Ahvaz Jundishapur University of Medical Sciences, Ahvaz, IR Iran \\ 2 Department of Statistics, School of Health, Ahvaz Jundishapur University of Medical Sciences, Ahvaz, IR Iran \\ 3 Department of Oncology, School of Medicine, Ahvaz Jundishapur University of Medical Sciences, Ahvaz, IR Iran \\ ${ }^{*}$ Corresponding author: Shahram Baraz, Chronic Diseases Care Research Center, School of Nursing and Midwifery, Ahvaz Jundishapur University of Medical Sciences, Ahvaz, IR Iran \\ Tel/Fax: +98-6133738333, E-mail: shahrambaraz@ajums.ac.ir
}

Received: February 9, 2015; Revised: March 15, 2015; Accepted: April 6, 2015

\begin{abstract}
Background: Chronic pain is one of the most prevalent symptoms in patients with acute leukemia and can affect patients' Quality of Life (QOL) that is a significant factor in assessment of cancer treatments. Also, the goal of curing hematological malignancies is to reach to increased survival and improvement of patients; and this goal will be fulfilled when QOL in patients is promoted.

Objectives: The present study aimed to investigate the correlation between chronic pain and Health-Related QOL (HR-QOL) in patients with acute leukemia under chemotherapy in Ahvaz City, Iran.

Patients and Methods: This descriptive-analytical study was performed on 90 patients (age range, 18 - 50 years) with acute leukemia under chemotherapy referred to Shafa Hospital in Ahvaz, Iran. The participants were selected through convenient sampling. The outcome measures included the Iranian version of the Short-Form 36 (SF-36) health survey, Numeric Rating Scale (NRS) for assessing the pain, and demographic questionnaire. Data analysis was performed using ANOVA, t-test, chi-square, with the significance level of $95 \%$.

Results: The average of pain severity was $6.03 \pm 2.06$, and the total average of HR-QOL was $46.83 \pm 3.62$, and the lowest average belonged to physical function $(42.17 \pm 25.75)$. No significant difference was found in the average pain between the two genders $(\mathrm{P}=0.487)$; however, there was a statistically significant difference between HR-QOL and gender $(P=0.005)$. Moreover, no significant difference was detected between the average pain severity and acute leukemia type $(\mathrm{P}=0.152)$. The findings also revealed a significant relationship between pain severity and aspects of HR-QOL, So that, all aspects of QOL were decreased with increased pain severity.

Conclusions: The results of the study indicate that chronic pain and HR-QOL in patients with acute leukemia in Ahvaz are in a very adverse condition and require serious reform. The findings of the study can be helpful in the clinical decisions and health care programs to the therapeutic team.
\end{abstract}

Keywords: Leukemia; Chronic Pain; Quality of Life; Chemotherapy

\section{Background}

Leukemia is among the neoplastic diseases that begin with abnormal changes of blood cells in bone marrow. Leukemia is a globally spread disease, and it is increasingly spreading in Iran (1). In 2013, leukemia developed in US in 48610 new people and caused 23720 deaths (2). According to Hadi et al. in Iran, the prevalence of leukemia in women aged between 15 - 49 years old was $13.89 \%$ among 100,000 person, and in men with the same range of age, the prevalence of the disease was $18.31 \%$ among 100,000 person (3). According to World Health Organization (WHO) report in 2008 , five common cancers in Iran are stomach, breast, colon-rectum, bladder and leukemia (4).

Chronic pain is one of the most important scary and annoying problems in patients with acute leukemia that are highly prevalent and it happens within a stage of cancer due to the disease or related treatments (5). Cancer treatments such as chemotherapy and radiotherapy may cause neuropathic, muscular, bone and joint pain (6). Regarded as a complex and unpleasant phenomenon, chronic pain causes feeling of hopelessness and worthlessness of life in patients with cancer. Also, it can inflict emotional, physical and social difficulties on the patients that can be costly for the patients or those around them (7). Chronic pain affects interpersonal relations and daily activities, and also postpones recovery (8). Performance of almost $69 \%$ of patients with cancer are affected by chronic pain, and $83 \%$ of leukemia and lymphoma patients suffer from chronic pain (9). Correct and on time pain relief will promote satisfaction and Quality of Life (QOL) in the patients (10). Despite many studies undertaken in the field, the pain in patients with cancer still remains as a clinical problem, and there appears to be a need for further studies over pain controlling (11). Pain

Copyright (C) 2015, Ahvaz Jundishapur University of Medical Sciences. This is an open-access article distributed under the terms of the Creative Commons Attribution-NonCommercial 4.0 International License (http://creativecommons.org/licenses/by-nc/4.0/) which permits copy and redistribute the material just in noncommercial usages, provided the original work is properly cited. 
management in cancer treatments plays a significant role in gaining the best possible results (12), and researchers argue that being aware of pain managements in cancer treatments is crucial for achieving any improvement (13). Also, at present, assessing the pain is in high priority in oncology and clinical nursing (14). On the other hand, in Ahvaz, no detail is available about the relation between chronic pain and its effects on QOL in patients with acute leukemia, who are symptomized by chronic pain as one of the main signs of their disease.

There is a close correlation between pain severity and QOL as it is argued that pain is one of the key factors in decreasing QOL in patients with cancer (12). World health organization has had a particular attention to development of QOL assessment and defines QOL as perception of life, values, goals, standards, and interests in each individual, which include physical, psychological, and social aspects of life (15). Quality of life is considered as one of the main concerns of policymakers and experts of public health team, and is used as an index in public health surveys (16); it also comprises a significant part of criteria of cancer treatment assessments that require QOL evaluation of patients in various regions (1). Gaining the information about QOL and discovering the level of patients' sense of well-being and recognizing the fields they do not have this sense, can be helpful for more effective treatments and future improvements of QOL (17). Assessment of QOL provides us with useful information about predicting consequences of the disease and evaluating the treatments for the clinical team, which as a result will improve quality of the health services. Moreover, improvements in health care services will create positive attitude and participations of patients in interventions; this attitudes and participations will lead to promotion of QOL in patients through a cyclic motion (18). Some researchers believe that the information about QOL can bring a scientific support for clinical decisions, and naturally, it may have better results for the patients (19). Also, the goal of curing hematological malignancies is to reach to increased survival and improvement of patients; and this goal will be fulfilled when QOL in patients is promoted (1). Chemotherapy, which remains as one of the main parts of treatment, is considered to be the most important factor on QOL in patients with acute leukemia (20). The study carried out by Musarezaie et al. in Isfahan, revealed that patients with leukemia had a low QOL, and there was an inverse relationship between pain severity and QOL in those patients (1). Furthermore, Redaelli et al. argued that AML (Acute myeloid leukemia) patients suffered a lower QOL than the individuals in the control group (20).

Regarding the relationship between pain and HealthRelated QOL (HR-QOL) in these patients, there were some controversies, which the present study attempted to clear. Moreover, at present, only drug control methods are applied in Ahvaz that neither are they applied according to international standards protocol nor is there any systematic trend for assessing the level of pain and QOL in patients with acute leukemia. Finally, due to fast prevalence of acute leukemia in Ahvaz as the only health center within the province, and also due to the lack of studies in the field of observing the increasing problems of such patients in clinics, the present study aimed to assess relationship between chronic pain and QOL of patients with acute leukemia in Ahvaz City, Iran. Understanding these factors will help the society's health workers in their efforts to improve the health and the QOL of these patients.

\section{Objectives}

The present study aimed to assess the relationship between chronic pain and HR-QOL in patients with acute leukemia under chemotherapy in Ahvaz Shafa Hospital in 2014.

\section{Patients and Methods}

\subsection{Study Design and Population}

This descriptive-analytical study was performed on 90 patients with acute leukemia referred to Shafa Hospital affiliated to Ahvaz Jundishapur University of Medical Sciences during 3 months. The participants were selected through convenient sampling. Using a statistical sampling formula with $\alpha=0.05, \sigma=27.08, d=$ one-fifth of a standard deviation; adopted from other studies (3) the number of sample was 96 . Due to the potential loss of samples, $15 \%-20 \%$ of this amount was added to the sample, thus the 116 patients in a 3-month sampling period (with convenience sampling) were enrolled (Equation 1).

$$
n=\frac{\left(Z_{1}-\frac{\alpha}{2}\right)^{2} \times \sigma^{2}}{d^{2}}
$$

Subjects' eligibility to participate in this study was based on the following inclusion criteria: 1 ) the age range from 18 to 50 years old, 2) intermittent or persistent pain for 3 months (chronic pain), 3) no sign of clear and identified pain disorders, which are recorded in patients' files (pains from lumbar disc, spinal injuries, fractures, etc.), 4) not having any background diseases (such as diabetes, peripheral nerve disease), 5) no drug addiction, 6) the patients should have been under chemotherapy for at least two sessions, and 7) no other malignancy records. Figure 1 shows the accrual process and attrition in more details.

\subsection{Measuring Tools}

The outcome measures include the Iranian version of the Short-Form 36 (SF-36) health survey, Numeric Rating Scale (NRS) for the pain assessment, and demographic questionnaire.FormeasuringtheQOL, theIranianversion 


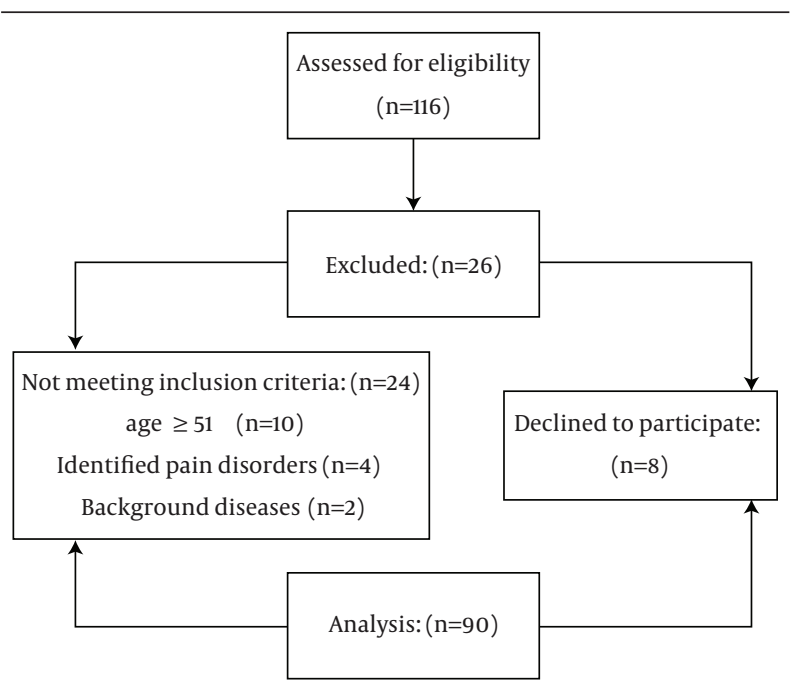

Figure 1. Flowchart of Study Accrual and Attrition

of SF-36 health survey was applied. It consists of eight subscales including physical functioning, role limitations owing to physical health problems, bodily pain, social performance, general mental health, role limitations owing to emotional health problems, energy and weariness, and general health perception. To do the scoring in each aspect, the total scores of each item was calculated, then it was modified into a scale ranging from zero (poorest condition) to one hundred (best condition). The three-choice questions were considered with the scores $(0,50,100)$, five-choice questions with $(0,25,50,75,100)$, and six-choice questions with $(0,20$, $40,60,80,100)$; and higher scores indicated better conditions. This tool has been interpreted and validated for use in HR-QOL assessment in Iran (21). Moreover, the permission of using this tool was gained from Dr. Montazeri, Persian author of this tool.

Numeric rating scale was used to survey the intensity of pain severity in the subjects. This tool is a 10-centimeter ruler which is pointed in its left side with zero (indicating there is no pain) and in the right side with the digit 10 (showing a severe pain). Scores 1-3 are considered as mild pain, 4-6 show moderate pain, 7-9 are recognized as severe pain and 10 being unbearable pain. Justifiability and perpetuity of this tool has been weighed by different studies $(22,23)$.

The survey included demographic questions regarding the participant's age, gender, education, and race. The leukemia type was also extracted from patients' records.

\subsection{Methods}

Considering the ethical considerations and obtaining the written informed consent from the patients, the researcher began to complete the questionnaires. Literate patients completed the questionnaires by themselves and for the rest it was completed through interviewing method. And if any of the patients had chemotherapy schedules, they were interviewed 2 to 3 hours before or after their treatment in order to ensure that patients were not suffering from any chemotherapy-related discomfort.

To fulfill the NRS, the patients' level of pain intensity was measured in different times of a day for three consecutive days; then the average pain was considered as the pain criterion for each subject.

\subsection{Data analyses}

Data analysis was performed by SPSS version 17 using descriptive-analytic statistics (mean, standard deviation, chi-square, t-test and ANOVA), with the significance level of $95 \%$.

\subsection{Ethical Considerations}

The researcher considered moral ethics through the study and, after explaining the goals of the study and optional participation, and also assuring them about confidentiality of the collected data. Finally, we asked the participants to read and sign the informed consent form. This study was approved in ethics committee of Ahvaz Jundishapur University of Medical Sciences (ethical code: ajums.rec.1393.388).

\section{Results}

According to the findings of the study, the average age of the patients was $33.83 \pm 9.38$ years, and most subjects of the study were male (53.3\%), Persian (50\%) and had highschool educations (40\%). The majority of the patients suffered from acute myeloid leukemia (76.7\%). The average pain severity was $6.03 \pm 2.06$, and most of the patients experienced moderate pain (43.3\%).

Moreover, the study revealed that the average of all aspects of QOL was $46.83 \pm 3.62$, while the lowest average belonged to physical function (42.17 \pm 25.75$)$, and highest average belonged to social function $(52.67 \pm 21.28)$ (Table 1$)$.

Table 1. Mean Score of Dimensions of Quality of Life in the Patients With Acute Leukemia (Short Form-36)

\begin{tabular}{lc}
\hline Dimensions & Means \pm SD \\
\hline Physical function & $42.17 \pm 25.75$ \\
\hline Physical role & $44.50 \pm 24.88$ \\
\hline Bodily pain & $42.33 \pm 28.22$ \\
\hline General health & $48.50 \pm 22.78$ \\
\hline Social functioning & $52.67 \pm 21.28$ \\
\hline Emotional role & $47.83 \pm 21.04$ \\
\hline Mental health & $49.33 \pm 18.84$ \\
\hline Vitality & $47.33 \pm 21.86$ \\
\hline Total of all dimensions & $374.66 \pm 173.744$ \\
\hline
\end{tabular}


Miladinia M et al.

The average pain severity in men appeared to be more than in women, but the difference was not significant ( $P$ $=0.487$ ), whereas there was a significant difference between men and women in their QOL as the average of all aspects of QOL was lower in men than in women (Table 2). The average pain severity in AML was more than that of ALL, but did not appear to be significant $(P=0.152)$. Moreover, although the total average of QOL aspects, except mental health, in AML patients was lower than in ALL patients, the difference was not very meaningful. According to the findings of the study, the lowest average of pain in AML patients belonged to physical function, and in ALL patients the lowest average was detected at their mental health (Table 3).

It was also revealed that there was a meaningful relationship between pain severity and QOL as with the increase in pain severity, all aspects of QOL were decreased (Table 4 ).

Table 2. Mean Score of Quality of Life, Leukemia Type, Pain and Age With Respect to the Gender a,b

\begin{tabular}{|c|c|c|c|}
\hline \multirow[t]{2}{*}{ Variables } & \multicolumn{2}{|c|}{ Gender } & \multirow[t]{2}{*}{ P Value } \\
\hline & Male & Female & \\
\hline Type of Leukemia & & & 0.058 \\
\hline AML & $33(68.8)$ & $36(85.7)$ & \\
\hline ALL & $15(31.2)$ & $6(14.3)$ & \\
\hline Pain & & & 0.487 \\
\hline Mild & $6(12.5)$ & $9(21.4)$ & \\
\hline Moderate & $21(43.8)$ & $15(35.7)$ & \\
\hline Severe & $21(43.8)$ & $18(42.9)$ & \\
\hline Age, $y$ & $34.94 \pm 8.73$ & $32.57 \pm 10.03$ & 0.235 \\
\hline Physical function & $36.56 \pm 22.29$ & $48.57 \pm 28.13$ & $0.028^{c}$ \\
\hline Physical role & $39.38 \pm 23.48$ & $50.36 \pm 25.40$ & $0.019^{c}$ \\
\hline Bodily pain & $33.75 \pm 24.65$ & $52.14 \pm 29.11$ & $0.005^{c}$ \\
\hline General health & $41.88 \pm 20.12$ & $56.07 \pm 23.51$ & $0.001^{c}$ \\
\hline Social functioning & $44.69 \pm 19.52$ & $61.79 \pm 19.65$ & $0.001^{c}$ \\
\hline Emotional role & $42.81 \pm 17.03$ & $53.57 \pm 23.76$ & $0.032^{c}$ \\
\hline Mental health & $42.81 \pm 15.46$ & $56.79 \pm 19.74$ & $0.001^{c}$ \\
\hline Vitality & $40.00 \pm 18.30$ & $55.71 \pm 22.78$ & $0.001^{c}$ \\
\hline Total of all dimensions & $321.88 \pm 148.45$ & $435 \pm 182.41$ & $0.005^{c}$ \\
\hline
\end{tabular}

a Abbreviations: AML, Acute myeloid leukemia; ALL, Acute lymphoblastic leukemia; QOL, Quality of life.

${ }^{b}$ Data are presented as Mean \pm SD and No.(\%).

c The difference is statistically significant.

Table 3. Mean Score of Pain and Quality of Life With Respect to the Leukemia Type a,b

\begin{tabular}{lccc}
\hline Variables & AML & All & P Value \\
\hline Pain itensity & & & 0.152 \\
\hline Mild & $9(13)$ & $6(28.6)$ & \\
\hline Moderate & $27(39.1)$ & $9(42.9)$ & 0.736 \\
\hline Severe & $33(47.9)$ & $6(28.6)$ & 0.135 \\
\hline Physical function & $39.13 \pm 25.83$ & $52.14 \pm 23.37$ & 0.739 \\
Physical role & $40.87 \pm 23.74$ & $56.43 \pm 25.35$ & 0.332 \\
Bodily pain & $38.91 \pm 28.29$ & $53.57 \pm 25.50$ & 0.410 \\
General health & $46.09 \pm 22.27$ & $56.43 \pm 23.19$ & 0.372 \\
Social functioning & $51.09 \pm 19.97$ & $57.86 \pm 24.92$ & 0.551 \\
Emotional role & $45.87 \pm 21.55$ & $54.29 \pm 18.25$ & 0.551 \\
\hline Mental health & $49.35 \pm 19.49$ & $49.29 \pm 16.97$ & 0.389 \\
\hline Vitality & $44.35 \pm 20.32$ & $57.14 \pm 24.31$ & $437.14 \pm 172.16$ \\
\hline Mean of all dimensions & $355.65 \pm 170.94$ & & \\
\hline
\end{tabular}

a Data are presented as mean \pm SD and No. (\%).

$\mathrm{b}$ independent t-test and chi-square test were used. 
Miladinia M et al.

\begin{tabular}{|c|c|c|c|c|}
\hline \multirow[t]{2}{*}{ Variables } & \multicolumn{3}{|c|}{ Pain Intensity } & \multirow[t]{2}{*}{ P Value } \\
\hline & Mild & Moderate & Severe & \\
\hline Physical function & $75.00 \pm 2.42$ & $54.17 \pm 14.61$ & $18.46 \pm 14.78$ & $<0.001^{\mathrm{C}}$ \\
\hline Physical role & $75.00 \pm 8.01$ & $54.17 \pm 17.17$ & $23.85 \pm 16.16$ & $<0.001^{\mathrm{c}}$ \\
\hline Bodily pain & $77.00 \pm 2.53$ & $54.58 \pm 18.33$ & $17.69 \pm 17.72$ & $<0.001^{\mathrm{C}}$ \\
\hline General health & $73.00 \pm 7.02$ & $60.00 \pm 17.32$ & $28.46 \pm 12.14$ & $<0.001^{\mathrm{C}}$ \\
\hline Social functioning & $77.00 \pm 2.53$ & $62.50 \pm 17.00$ & $34.23 \pm 10.85$ & $<0.001^{\mathrm{C}}$ \\
\hline Emotional role & $70.00 \pm 8.66$ & $57.08 \pm 19.36$ & $30.77 \pm 9.49$ & $<0.001^{\mathrm{C}}$ \\
\hline Mental health & $70.00 \pm 8.66$ & $57.08 \pm 14.99$ & $34.23 \pm 11.72$ & $<0.001^{\mathrm{C}}$ \\
\hline Vitality & $73.00 \pm 7.02$ & $56.25 \pm 18.18$ & $29.23 \pm 11.21$ & $<0.001^{\mathrm{C}}$ \\
\hline Total of all dimensions & $590.00 \pm 13.49$ & $455.83 \pm 120.56$ & $246.92 \pm 84.63$ & $<0.001^{\mathrm{C}}$ \\
\hline
\end{tabular}

\section{Discussion}

The findings of the research showed that acute leukemia is more prevalent amongst men, and AML is the most common type of it. These results are consistent with those of Musarezaie (1), Hadi (3), and Zand (24) that were carried out in Iran. Also, the reports by US Society of Hematology (2009) indicate that different types of blood cancer do not equally happen in men and women. This proportion is not the same in various countries, and blood cancer is most common in men (25).

Regarding the pain severity, $43.3 \%$ of patients suffered moderate pain while in Musarezaie study carried out in Isfahan $86.95 \%$ of patients suffered moderate pain (1). The reason for this statistical difference is that level of pain is a mental concept and different people have different reactions to it; besides, cultural and racial factors, and personal, family and social problems affect the concept of pain in each person. Furthermore, treatments and pain controlling are not the same in different areas. Hence, such factors highlight the necessity for surveying and assessing pain severity in order to use the results for adopting medical and nonmedical approaches for pain controlling.

The results of the study indicated that the total average of different aspects of QOL is 46.83 that is consistent with the work of Hadi et al. who found the total average of different aspects of QOL in leukemia patients to be 47.19 (3). These similar results suggest that perhaps those who suffer from leukemia in Iran do not have a desirable QOL and therefore, regarding QOL as one of the main criteria of assessing cancer treatments, we must adopt new policies to reform it. Also, by researching in the field, we should identify the reasons and levels of their problems so as to proceed towards carrying out proper measurements.

The present study identified the physical function to have the lowest average among all aspects of QOL, while
Hadi et al. (3) and Eyigor et al. (26) argued that lowest average belonged to physical role. These incongruous results may be due to cultural, racial, and social differences. However, it is noteworthy that in our study as well as in other two mentioned studies, most problems in front of patients are physical aspects that maybe it is because when patients suffer from pain, they suffer from not only physical discomfort but also performativity restrictions which lead to their incapability. Ripamonti et al. (9) suggested that the performativity in $69 \%$ of individuals with cancer is directly affected by chronic pain they suffer.

The results of the study indicated that the highest average belonged to patients' social functioning. The same results were found by Karami et al. (27), and Tabari et al. (28). Despite these findings, Eyigor et al. (26) argued that the lowest average of QOL in patients with cancer belonged to physical role and social function. The more desirable quality of social functioning found in Iranian studies can be a result of supports of family, friends, and others when an individual suffers or faces a problem; this fact makes the social performance of the patient to improve. However, Eyigor's study claimed that the highest average belonged to bodily pain; so, this can indicate a better pain controlling condition in that country than in Iran (26).

The study found that men experienced a higher average of pain severity than women, though the difference was trivial $(\mathrm{P}=0.487)$. While chronic pain is a prevalent problem among patients with cancer, the dilemma about the effects of gender on this issue still remains unsolved and researches on the field have come to different conclusions over this problem (29). Studies such as Miaskowski et al. (30), Pud et al. (22), Edrington et al. (31), and Zimmermann et al. (23) as well as this research agree upon the fact that gender differences are not related to the level of pain severity. Another study by Pud (2011) indicated 
a significant relation between gender and pain; despite what the present research has brought up, Pud argued that the average of pain severity was higher in women, with a meaningful difference $(P=0.031)(32)$. This incongruity of results may be related to the fact that Pud surveyed patients with all types of cancers, while the present research's population only consisted of patients with leukemia; besides, the patients in Pud's study had a higher age average. Moreover, factors such as cultural, racial, social, nutritional and emotional diversity may be the reason for the difference in these results. In addition, the study suggested a significant statistical difference in average QOL between males and females as the total average in all aspects of QOL in men was lower than in women. The result of the present study agreed with what Pud found over the differences of QOL between two genders, although despite what was revealed in this study Pud's research indicated a lower average of QOL in women (32). Ethnicity and racial diversity, different population scale and also various types of cancers in the two studies can be the reason for this incongruity.

The results indicated that the type of leukemia does not have a meaningful statistical effect on QOL of the patients. Hadi et al. (3) reveled the same results as the present research. This ineffectiveness may be due to the fact that all leukemia patients undergo chemotherapy and almost have to deal with the same consequences and problems, and also, they all suffer mental and financial difficulties. In addition, both types are among acute diseases. Moreover, the results of the present study revealed that there was a meaningful relationship between the pain severity and different aspects of QOL as any increase in pain average would lead to decrease of QOL. This outcome is in congruity with the studies by Pud and Cheng et al. $(32,33)$. This may come from the fact that pain, as a complex and unpleasant factor, can inflict its malignant emotional, physical and social effects on patients, and let them, their families and society down and make them scared (7). The relation between chronic pain and the QOL suggests pain treatment to be put in priority of medicals' agenda in order to improve the QOL in patients (26).

The results of the study indicated that chronic pain and QOL in patients with acute leukemia in Ahvaz are in a very adverse condition and improving the patients' QOL requires serious structural reform in health care, rehabilitation, financial aids, and social support, and policymakers should provide proper healthcare measures for these patients; This unpleasant situation may be a result of disorders existing in different fields including healthcare team, family and social support, and several other factors. If medical staffs do not have access to information about the QOL of patients and symptoms such as chronic pain, they may choose the wrong treatments for each patient (34). The results of the present study showed that the conditions with which patients with acute leukemia are dealing, can help nurses who spend a great amount of time with such patients to have a good effect on health- care measures. These nurses can use such information to reform their actions and adopt new approaches to help them improve the conditions of those patients. Moreover, nurses can teach proper nondrug pain controlling methods to help them improve their QOL. Physicians can also adopt new and appropriate drug-based methods to control pain in such patients so as to play a great role in improving the QOL in them. On the one hand, the present study suggests that patients with acute leukemia mostly suffer from physical problems; hence, appropriate rehabilitative activities should be adopted as well as other healthcare measures for these patients.

Finally, it is suggested that the same study be carried out with a larger sample size covering a wider range of age groups to reach a better understanding of the problems such patients have to deal with. Moreover, a survey on other factors affecting QOL such as tiredness, sleep disorders, and mental disorders is highly recommended.

\section{Acknowledgements}

We are grateful to those who have helped us in this research. This project was approved and financially supported by Ahvaz Jundishapur University of Medical Sciences. This article was extracted from the Master's dissertation of the first author.

\section{Authors' Contributions}

Study concept and design: Shahram Baraz. Acquisition of data: Mojtaba Miladinia. Analysis and interpretation of data: Mojtaba Miladinia, and Amal Saki Malehi. Drafting of the manuscript: Mojtaba Miladinia, and Shahram Baraz. Critical revision of the manuscript for important intellectual content: Shahram Baraz. Statistical analysis: Amal Saki Malehi. Administrative, technical, and material support: Shahram Baraz, and Abdolali Shariati. Study supervision: Shahram Baraz, and Abdolali Shariati.

\section{Funding/Support}

This project was funded and supported by research department of Ahvaz Jundishapur University of Medical Sciences.

\section{References}

1. Musarezaie A, Khaledi F, Esfahani HN, Ghaleghasemi TM. Factors affecting quality of life and fatigue in patients with leukemia under chemotherapy.J Educ Health Promot. 2014;3:64.

2. Siegel R, Naishadham D, Jemal A. Cancer statistics, 2013. CA Cancer J Clin. 2013;63(1):11-30.

3. Hadi N, Namvar E, Montazeri A. [Quality of life connection with health in the adult with leukemia]. Payesh .2011;10(2):151-6.

4. Rohani M, Rohani MR, Rahimi F, Mehrazma M, Golmohammadi A. [Distribution of cancer incidence in districts and neighbourhoods of a number of Tehran districts]. Razi J. 2011;11(89):34-45.

5. Ghafari S, Karami M, Hasanpour E. Comprehensive review of medical-surgical nursing on the basis of Brunner, Black and Phips. 6th edTehran: Jame negar; 2011.

6. Engwall M, Duppils GS. Music as a nursing intervention for postoperative pain: a systematic review. J Perianesth Nurs. 2009;24(6):370-83. 
7. Yeganekhah MR, Abedini Z, Dadkhah Tehrani T. [Evaluation of an Applied Method in Reducing the Pain of Intramuscular Injection]. Qom Univ Med Sci J. 2013;7(1):57-62.

8. Hinkle JL, Cheever K. H. . Brunner \& Suddarth's Textbook of MedicalSurgical Nursing. 13th ed; 2013.

9. Ripamonti CI, Santini D, Maranzano E, Berti M, Roila F, Esmo Guidelines Working Group . Management of cancer pain: ESMO Clinical Practice Guidelines. Ann Oncol. 2012;23 Suppl 7:vii139-54.

10. Breunis H, Timilshina N, Brandwein J, Minden M, Gupta V, Buckstein R, et al. Recovery of Quality of Life (QOL) and Physical Function are Similar Over One Year in Older and Younger Survivors with Acute Myeloid Leukemia (AML) Undergoing Intensive Chemotherapy. J Geriatr Oncol. 2013;4:S18-9.

11. Valeberg BT, Kolstad E, Smastuen MC, Miaskowski C, Rustoen T. The PRO-SELF pain control program improves family caregivers' knowledge of cancer pain management. Cancer Nurs. 2013;36(6):429-35.

12. Swarm RA, Abernethy AP, Anghelescu DL, Benedetti C, Buga S, Cleeland C, et al. Adult cancer pain. J Natl Compr Canc Netw. 2013;11(8):992-1022.

13. Borneman T, Koczywas M, Sun VC, Piper BF, Uman G, Ferrell B. Reducing patient barriers to pain and fatigue management. J Pain Symptom Manage. 2010;39(3):486-501.

14. Kim HJ, Malone PS, Barsevick AM. Subgroups of cancer patients with unique pain and fatigue experiences during chemotherapy. J Pain Symptom Manage. 2014;48(4):558-68.

15. Isikhan V, Guner P, Komurcu S, Ozet A, Arpaci F, Ozturk B. The relationship between disease features and quality of life in patients with cancer--I. Cancer Nurs. 2001;24(6):490-5.

16. Rahman A. Quality of life with treated acute promyelocytic leukaemia. Lancet Oncol. 2014;15(12):e533.

17. Kim DH, Chung NG, Lee S. The Effect of Perceived Parental Rearing Behaviors on Health-Related Quality of Life in Adolescents with Leukemia.J Pediatr Oncol Nurs. 2015.

18. Salehi M, Shariati A, Ansari M, Latifi M. Effect of Benson Relaxation Therapy on Quality of Life (QOL) in Breast Cancer Patients Undergoing Chemotherapy. Jundishapur J Chronic Dis Care. 2012;1(1):1-8.

19. Montazeri A. Health-related quality of life in breast cancer patients: a bibliographic review of the literature from 1974 to 2007. J Exp Clin CancerRes. 2008;27(1):32.

20. Redaelli A, Stephens JM, Brandt S, Botteman MF, Pashos CL. Shortand long-term effects of acute myeloid leukemia on patien health-related quality of life. Cancer Treat Rev. 2004;30(1):103-17.

21. Montazeri A, Goshtasebi A, Vahdaninia MS. [The Short Form
Health survey (SF-36): translation and validation study of Iranian version]. Payesh . 2006;5:49-56.

22. Pud D, Ben Ami S, Cooper BA, Aouizerat BE, Cohen D, Radiano R, et al. The symptom experience of oncology outpatients has a different impact on quality-of-life outcomes. J Pain Symptom Manage. 2008;35(2):162-70.

23. Zimmermann C, Burman D, Follwell M, Wakimoto K, Seccareccia D, Bryson J, et al. Predictors of Symptom Severity and Response in Patients With Metastatic Cancer. Am J Hospice Palliat Med. 2009;27(3):175-81.

24. Zand AM, Imani S, Saadati M, Borna H, Ziaei R, Honari H. Effect of age, gender and blood group on blood cancer types. Kowsar Med. 2010;15(2):111-4

25. Arthur S. Last reviewed leukemia statistics. Chicago: American Medical Association; 2007. Available from: www.emedtv.com/ advertise.html.

26. Eyigor S, Eyigor C, Uslu R. Assessment of pain, fatigue, sleep and quality of life (QoL) in elderly hospitalized cancer patients. Arch Gerontol Geriatr. 2010;51(3):e57-61.

27. Karami O, Falahat-Pisheh F, Jahani hashemi H, Beiraghdar N. [Quality of life in cancer patient in Qazvin].JQUMS. 2010;14(3):80-6.

28. Tabari F, Zakeri Moghadam M, Bahrani N. [Evaluation of the quality of life in newly recognized cancer patients]. Hayat. 2007;13(2):5-12.

29. Fillingim RB, King CD, Ribeiro-Dasilva MC, Rahim-Williams B, Riley J3. Sex, gender, and pain: a review of recent clinical and experimental findings.J Pain. 2009;10(5):447-85.

30. Miaskowski C, Cooper BA, Paul SM, Dodd M, Lee K, Aouizerat BE, et al. Subgroups of patients with cancer with different symptom experiences and quality-of-life outcomes: a cluster analysis. Oncol Nurs Forum. 2006;33(5):E79-89.

31. Edrington JM, Paul S, Dodd M, West C, Facione N, Tripathy D, et al No evidence for sex differences in the severity and treatment of cancer pain. J Pain Symptom Manage. 2004;28(3):225-32.

32. Pud D. Gender differences in predicting quality of life in cancer patients with pain. Eur J Oncol Nurs. 2011;15(5):486-91.

33. Cheng KK, Lee DT. Effects of pain, fatigue, insomnia, and mood disturbance on functional status and quality of life of elderly patients with cancer. Crit Rev Oncol Hematol. 2011;78(2):127-37.

34. Hwang SS, Scott CB, Chang VT, Cogswell J, Srinivas S, Kasimis B. Prediction of survival for advanced cancer patients by recursive partitioning analysis: role of Karnofsky performance status, quality of life, and symptom distress. Cancer Invest. 2004;22(5):678-87. 